\title{
Effects of very early start of norepinephrine in patients with septic shock: a propensity score-based analysis
}

\author{
Gustavo A. Ospina-Tascón ${ }^{1,2^{*}}$ (D), Glenn Hernandez³ ${ }^{3}$ Ingrid Alvarez', Luis E. Calderón-Tapia', \\ Ramiro Manzano-Nunez ${ }^{1}$, Alvaro I. Sánchez-Ortiz ${ }^{1}$, Egardo Quiñones ${ }^{1}$, Juan E. Ruiz-Yucuma ${ }^{1}$, José L. Aldana ${ }^{1,2}$, \\ Jean-Louis Teboul ${ }^{4}$, Alexandre Biasi Cavalcanti ${ }^{5}$, Daniel De Backer ${ }^{6}$ and Jan Bakker ${ }^{3,7,8,9}$
}

\begin{abstract}
Background: Optimal timing for the start of vasopressors (VP) in septic shock has not been widely studied since it is assumed that fluids must be administered in advance. We sought to evaluate whether a very early start of VP, even without completing the initial fluid loading, might impact clinical outcomes in septic shock.

Methods: A total of 337 patients with sepsis requiring VP support for at least $6 \mathrm{~h}$ were initially selected from a prospectively collected database in a 90-bed mixed-ICU during a 24-month period. They were classified into veryearly (VE-VPs) or delayed vasopressor start (D-VPs) categories according to whether norepinephrine was initiated or not within/before the next hour of the first resuscitative fluid load. Then, VE-VPs $(n=93)$ patients were 1:1 propensity matched to D-VPs ( $n=93$ ) based on age; source of admission (emergency room, general wards, intensive care unit); chronic and acute comorbidities; and lactate, heart rate, systolic, and diastolic pressure at vasopressor start. A riskadjusted Cox proportional hazard model was fitted to assess the association between VE-VPs and day 28 mortality. Finally, a sensitivity analysis was performed also including those patients requiring VP support for less than $6 \mathrm{~h}$.

Results: Patients subjected to VE-VPs received significantly less resuscitation fluids at vasopressor starting (0[0-510] vs. $1500[650-2300] \mathrm{mL}, p<0.001)$ and during the first $8 \mathrm{~h}$ of resuscitation (1100[500-1900] vs. 2600[1600-3800] $\mathrm{mL}, p<$ 0.001 ), with no significant increase in acute renal failure and/or renal replacement therapy requirements. VE-VPs was related with significant lower net fluid balances 8 and $24 \mathrm{~h}$ after VPs. VE-VPs was also associated with a significant reduction in the risk of death compared to D-VPs (HR 0.31, C195\% 0.17-0.57, $p<0.001)$ at day 28. Such association was maintained after including patients receiving vasopressors for $<6 \mathrm{~h}$.
\end{abstract}

Conclusion: A very early start of vasopressor support seems to be safe, might limit the amount of fluids to resuscitate septic shock, and could lead to better clinical outcomes.

Keywords: Septic shock, Norepinephrine, Vasopressor support, Clinical outcomes

\section{Background}

Early detection and prompt reversion of sepsis-induced tissue hypoperfusion are key elements in the treatment of patients with septic shock [1,2]. Fluid administration is widely accepted as the first-line therapy followed by

\footnotetext{
* Correspondence: gusospin@gmail.com

'Department of Intensive Care Medicine, Fundación Valle del Lili, Universidad Icesi, Cali, Colombia

${ }^{2}$ Translational Medicine Laboratory in Critical Care and Advanced Trauma

Surgery, Fundación Valle del Lili, Universidad Icesi, Cali, Colombia

Full list of author information is available at the end of the article
}

vasopressor use in persistently hypotensive patients or in those in whom arterial pressure is judged to be insufficient to ensure an adequate tissue perfusion [2]. Studies on implementation of therapeutic bundles in sepsis $[3,4]$ and recent randomized controlled trials on early goal-directed therapy in septic shock [5-7] highlighted the importance of the initial fluid loading and turned this into a standard for the clinical practice. Indeed, current guidelines on sepsis management emphasize on the administration of at least $30 \mathrm{~mL} / \mathrm{kg}$ of IV crystalloids within the first $3 \mathrm{~h}$ of identification of sepsis-induced hypoperfusion, but a

(C) The Author(s). 2020 Open Access This article is distributed under the terms of the Creative Commons Attribution 4.0 International License (http://creativecommons.org/licenses/by/4.0/), which permits unrestricted use, distribution, and 
recommendation on the timing to start vasopressor support was not clearly stated [1]. Nevertheless, a recent update on the last recommendations of Surviving Sepsis Campaign claims for an immediate start of resuscitation and treatment in a "1-h bundle" [8] including the use of vasopressors in the case of life-threatening hypotension, during or after fluid resuscitation to maintain a MAP $\geq 65 \mathrm{mmHg}$. Although this initiative embraces the concept of sepsis as a medical emergency, the level of evidence for these recommendations [8] is quite limited and remains debatable.

Recent studies have questioned the clinical benefit of fluid boluses in patients with sepsis and hypotension [9, 10]. In line with this, recent experimental data suggested that fluid resuscitation preceding the start of vasopressors is associated with higher lactate levels and a paradoxical increase in vasopressor requirements when compared with an immediate start of vasopressor therapy without previous fluid administration [11]. Likewise, a number of observational studies suggest that the volume of resuscitation fluids and net fluid balance is associated with mortality in sepsis [12-24]. Nevertheless, other data indicates that vasopressors should be administered in combination with fluids since isolated vasopressors can improve arterial pressure but not regional blood flow [25].

An early start of vasopressor therapy may have several beneficial effects. First, norepinephrine may increase cardiac output by increasing stressed volume [26], by improving myocardial contractility [27], and through other various mechanisms [28]. Second, norepinephrine might increase microcirculatory perfusion in septic shock [29-31], especially when the baseline microcirculatory blood flow is abnormal [32]. Third, early use of norepinephrine may improve the regional distribution of blood flow and prevent fluid overload [25]. Finally, delays in correcting hypotension are associated with increased risk of death in septic patients [33-35], whereby prompt correction of hypotension might influence clinical outcomes. Indeed, a recent phase II randomized controlled trial suggested that early use of norepinephrine might improve the possibility to achieve more sustained mean arterial pressure levels and adequate tissue perfusion parameters [36]. However, this trial was limited by a specificity of the protocol requesting administration of a fixed dose of vasopressors in the early group, which is not the usual way of administering vasopressors.

Since the optimal timing of the introduction of vasopressors remains unknown and whether the benefits or harm of vasopressor introduction even preceding fluid resuscitation has not been still answered, we evaluated the impact of very early and the concurrent start of vasopressor support and fluid resuscitation on clinical outcomes in patients with septic shock.

\section{Methods}

\section{Study population}

Adult patients $>18$ years or older fulfilling the diagnostic criteria for septic shock stated in the Surviving Sepsis Campaign: International Guidelines for Management of Severe Sepsis and Septic Shock: 2012 [37] and based on the previous $2001 \mathrm{SCCM} / \mathrm{ESICM} / \mathrm{ACCP} / \mathrm{ATS} / \mathrm{SIS}$ International Sepsis Definitions Conference [38] were prospectively collected between January 2015 and February 2017 in one mixed-ICU in a university hospital in Colombia (Fundación Valle del Lili, Cali, Colombia). This original definition was maintained as inclusion criteria since it was valid during the period in which the database was constructed. The ethical and research committee involving human beings approved the use of the data (Protocol number 1238, IRB/EC approval number 099-2018, Fundación Valle del Lili, Cali, Colombia). The presence of infection was determined according to the Centers for Diseases Control and Prevention criteria [39]. For analysis purposes, however, septic shock was re-classified according to the current Third International Consensus Definitions for Sepsis and Septic Shock (Sepsis 3.0), which consider the presence of suspected infection accompanying organ dysfunction, the use of vasopressors, MAP $<65 \mathrm{mmHg}$, and lactate levels $>2 \mathrm{mmol} / \mathrm{L}$ [40]. Meanwhile, patients with sepsis and vasopressor requirement but without hyperlactatemia were reclassified and analyzed as sepsis-related acute circulatory failure. Surviving patients requiring less than $6 \mathrm{~h}$ of vasopressor support were not included in the initial main analysis, as they could not be representative of septic shock. Nevertheless, these patients were also evaluated in an ulterior sensitivity analysis. Patients $<18$ years old, pregnant women, patients with liver failure (prothrombin time $>15 \mathrm{~s}$ or international normalized ratio $\geq 1.5$ and any hepatic encephalopathy), advanced liver cirrhosis (Child-Pugh $\mathrm{C}$ ), and those with do-not-resuscitate orders were excluded.

\section{Study design}

Very early start of vasopressor (VE-VPs) was defined as that vasopressor support initiated within the next hour or even before the first fluid load with resuscitative intention (FRLoad). Those patients in whom vasopressor support was started $>1 \mathrm{~h}$ after the FRLoad were classified as delayed VPs (D-VPs). In each case, the start of vasopressor (VPs) was identified and used as a reference point to determine the time elapsed from the first hypotension episode (FHypo) and from the FRLoad. The decision to start vasopressor support was always taken by the attending physician according to his clinical judgment. The delay time until the start of antibiotics was also recorded with respect to the first hypotension episode. In addition, time intervals from FHypo, FRLoad, and VPs up to ICU admission were 
also recorded. The volume of resuscitation fluids received before VPs was also registered. Then, the volume of resuscitation fluids and dose of vasopressors were recorded at 2-h intervals from the VPs up to $8 \mathrm{~h}$, and then, 12, 18, and $24 \mathrm{~h}$ after VPs. Net fluid balance was also recorded at FHypo, FRLoad, VPs, and also $8 \mathrm{~h}(8 \mathrm{H})$ and $24 \mathrm{~h}(24 \mathrm{H})$ after the start of vasopressor support.

General demographics including age, APACHE II, comorbidities, and origin of the patient (emergency room, general ward, or intensive care unit) were registered. Heart rate and arterial pressure were also recorded at FHypo, FRLoad, VPs, and at 2, 4, 6, 8, and $24 \mathrm{~h}$ after the VPs. Multiple organ dysfunction was assessed using the Sequential Organ Failure Assessment Score (SOFA) [41]. Ventilator-free days, requirement of renal replacement therapy (RRT), and RRT-free days were also calculated. Finally, ICU and hospital length of stay were recorded along with UCI, in-hospital, and 28 days of mortality.

\section{General management}

Patients followed an early quantitative resuscitation protocol aiming to target: (a) MAP $\geq 65 \mathrm{mmHg}$; (b) urine output $>0.5 \mathrm{~mL} / \mathrm{kg} / \mathrm{min}$; (c) $\mathrm{ScvO}_{2} \geq 70 \%$, when available; and (d) normalization of lactate levels or decreasing of $20 \%$ each $2 \mathrm{~h}$ in lactate levels. Fluid resuscitation was performed administering repeated fluid challenges with crystalloids and/ or albumin $4 \%$, using the central venous pressure (CVP) as a dynamic safety limit during fluid loads in patients with a central line in place. Hydroxyethyl starches (HES) were not used. The usual protocol in our institution includes the use of pulse pressure and stroke volume variations to guide fluid resuscitation (when usable). Additionally, echocardiographic determination of velocity-time integral (VTI) before and after passive leg raising (PLR), and end-expiratory occlusion maneuvers were used whenever applicable. The clinical assessment of peripheral perfusion (e.g., measuring capillary refill time [42] and/or the evaluation of mottling score [43]) and the use of advanced monitoring of cardiac output were allowed at the discretion of the attending physician. Norepinephrine was the first-choice vasopressor used to achieve MAP $\geq 65$, while vasopressin titrated up to $0.04 \mathrm{UI} / \mathrm{min}$ was also allowed to increase MAP or to decrease norepinephrine dose, but never as a single vasopressor. Dobutamine up to $20 \mu \mathrm{cg} / \mathrm{kg}$ min was used in case of myocardial dysfunction, when $\mathrm{ScrO}_{2}$ or lactate goals were not achieved or when clinical signs of hypoperfusion persisted despite adequate fluid resuscitation. Mechanical ventilation was used when indicated, providing light sedation (midazolam or propofol) and analgesia (fentanyl). Red blood cell transfusion was used to maintain hemoglobin levels at or above $7.0 \mathrm{~g} / \mathrm{dl}$ or $>10.0 \mathrm{~g} / \mathrm{dl}$ in case of cardiac ischemia. Low-dose hydrocortisone was used when the vasopressor requirement did not decrease during the first $6 \mathrm{~h}$ of resuscitation in the presence of an adequate intravascular volume. Glycemic control was adjusted to maintain glucose levels $<150 \mathrm{mg} / \mathrm{dL}$, while thrombosis prophylaxis and stress ulcer protection were also provided according to international guidelines valid at the time in which patients were treated [37].

\section{Statistical analysis}

Patients meeting eligibility criteria and subjected to VEVPs were propensity-matched with those subjected to DVPs. For that, factors potentially influencing the decision of very early vasopressor support such as source of admission (emergency room, intensive care unit), age, chronic, and acute comorbidities (hypertension, coronary disease, chronic heart failure, end-stage renal failure, chronic atrial fibrillation, chronic use of steroids, previous stroke, diabetes, cancer, chronic obstructive pulmonary disease, cirrhosis Child-Pugh $\mathrm{C}$, acute myocardial infarction, acute heart failure, acute stroke, acute atrial fibrillation), diastolic blood pressure, systolic blood pressure and heart rate at the VPs, the heart rate/diastolic blood pressure ratio at the FRLoad, and arterial lactate levels at the VPs were included in a logistical model to estimate the propensity scores. After fitting the propensity score, a nearest neighbormatching algorithm extracted 1:1 matched pairs of VE-VPs and D-VPs individuals. The effect of early start of vasopressors on mortality at day 28 was assessed using a Coxproportional hazards model adjusted by SOFA score at day 1 , the presence of hyperlactatemia (septic shock according to Sepsis 3.0 definition), delay time of antibiotic administration, and the net fluid balance at $24 \mathrm{~h}$. In addition, adjunctive therapies (e.g., renal replacement therapies, vasopressin, and steroid use) were also used as covariables. A conditional forward stepwise technique was used after verifying all subsets selection, while the proportional hazards assumption was tested on the basis of Schoenfeld residuals.

Repeated measures ANOVA were used to evaluate the time-course of vasopressor dose and cumulated resuscitation fluids during the first $8 \mathrm{~h}$ of resuscitation and the inter-group differences between VE-VPs and D-VPs.

Supplementary sensitivity analysis was conducted to evaluate the relationship between VE-VPs and mortality at day 28. For this, those patients receiving vasopressor support for less than $6 \mathrm{~h}$ were included to construct a new propensity-matching algorithm followed by a new Cox-proportional hazards model adjusted by the same covariables. Continuous variables were compared using non-parametric test and data are presented as medians (25th-75th percentiles). A $p<0.05$ was considered statistically significant.

\section{Results}

From 646 patients screened, 337 patients were finally included in the study (Additional file 1: Figure S1). For the analysis, 239 were re-classified as septic shock (Sepsis 
3.0 definition), while 98 were re-classified as a sepsisrelated acute circulatory failure. The mortality of the entire cohort at 28 days was $38.3 \%$, while the length of ICU and hospital stay were 9 [4-16] and 14 [6-29] days, respectively. A STROBE statement checklist for observational studies is provided in Additional file 1: Table S1.

Vasopressor support was initiated before or within the next hour of the first fluid resuscitation load (VE-VPs group) in 93 patients, while in the remaining 244, it was started $>1 \mathrm{~h}$ after the FRLoad (D-VPs group). General characteristics of the pre-matched groups are presented in Additional file 1: Table S2. Patients in the prematched D-VPs group had lower diastolic and mean arterial blood pressures at VPs, and they also had slightly higher heart rate to diastolic pressure ratios at the time of norepinephrine administration (Additional file 1: Table S2). Nevertheless, after the 1:1 propensity matching, VE-VPs $(n=93)$ and D-VP $(n=93)$ groups were adequately balanced (Table 1 ). Time elapsed between the first hypotension episode and the start of VP support (FHypo-to-VPs interval) was significantly longer in the D-VPs group. However, there were no significant differences in the time from VPs, FRLoad, and FHypo up to ICU admission (Table 1). There were also no significant differences in the time-course of mean arterial pressure after the start of vasopressor support (Additional file 1: Figure S2).

The volume of resuscitation fluids in the pre-vasopressor period (i.e., the FRLoad-to-VPs interval) was significantly lower in the VE-VPs (Table 1). Similarly, patients in the VE-VPs received less resuscitation fluids into the first $8 \mathrm{~h}$ of resuscitation (repeated measures ANOVA, inter-group difference, $p<0.001$; time"group interaction, $p=0.04$ ) represented by lower volumes at the start of vasopressors and less steep increases in cumulated resuscitation fluids at the end of such resuscitation period (Fig. 1, Table 1). Meanwhile, the net fluid balance at VPs, 8 and $24 \mathrm{~h}$, was significantly higher in the D-VPs group (repeated measures ANOVA, inter-group difference, $p<0.001$; time"group interaction, $p<0.001$ ) (Additional file 1: Figure S3).

There were no significant differences between VE-VPs and D-VPs groups regarding the maximal dose of norepinephrine, steroids and vasopressin use, or requirement of RRT (Table 1). Similarly, the time-course of norepinephrine doses, heart rate to diastolic pressure ratio, and pulse pressure was not significantly different between groups (Additional file 1: Figures S4, S5, S6). No cases of severe digital or severe vasopressor-induced splanchnic ischemia were documented.

The Cox-proportional hazard model revealed a significant decreased risk of death at day 28 for VE-VPs (HR 0.31 , CI95\% 0.17-0.57, $p<0.001$ ) (Fig. 2, Table 2). The beneficial effect of VE-VPs remained in patients fulfilling the septic shock criteria according to the Sepsis 3.0 definition (HR 0.40; 95\% CI, 0.21-0.74; $p=0.004$ ) (Additional file 1: Figure S7a). Information about the Coxproportional hazard models in the non-matched population is provided in Additional file 1: Table S3.

A sensitivity analysis including patients that used vasopressor support for $<6 \mathrm{~h}$ also demonstrated that VE-VPs is related with a significant lower risk of death at day 28 (HR 0.47, CI95\% 0.26-0.85, $p=<0.013$ ) (Additional file 1: Table S4).

\section{Discussion}

Two key points can be extracted from our observations: (a) a very early start of vasopressor support is associated with less use of resuscitation fluids, less fluid accumulation, and possibly, shortening of hypotension time; (b) very early start of vasopressors was not associated with increased kidney injury or ischemia-related adverse effects; but rather, it might decrease mortality in patients with septic shock.

Resuscitation of septic shock is currently based on fluid administration as first-line therapy followed by vasopressor support when the patient is supposed to become nonfluid responsive. Although widely accepted, this practice is not clearly supported by the evidence. In fact, information about the "pre-vasopressor" period in septic shock is quite limited because most of the current evidence on early goal-directed resuscitation comes from randomized controlled trials in which patients received a pre-determined amount of fluids as a prerequisite to be included (5-7). We retrospectively studied this "pre-vasopressor" phase in patients with sepsis requiring VP support for at least $6 \mathrm{~h}$, followed by a sensitivity analysis including a minority using VP support for less than $6 \mathrm{~h}$. Those in which VP was started $<1 \mathrm{~h}$ from the first fluid load (VE-VPs) received significantly less amount of resuscitation fluids at both pre-vasopressor and early resuscitation period, the net fluid accumulation at 8 and $24 \mathrm{~h}$ was significantly lower and they also had a significant lower mortality.

Observational studies and post hoc analysis of previous clinical trials suggest that greater accumulation of fluids is related with worse clinical outcomes [12, 18, 44], which agree with our results. Such effect of VE-VPs on the lower net fluid accumulation in our study was apparently mediated by the limiting fluid administration more than by increased fluid elimination. Although the lower mortality of patients in which norepinephrine was precociously initiated might have several potential explanations, a more rapid restoration of blood flow in combination with lower fluid accumulation could early restitute tissue perfusion and avoid the harm mediated by fluid overload. Interestingly, VE-VPs patients had the same blood pressure at time of first fluid bolus as patients with D-VPs, suggesting that the differences between groups were related to the timing of vasopressor initiation more than to the severity of hypotension. 
Table 1 General characteristics, hemodynamics, perfusion parameters, fluids, vasopressors, and outcomes for the propensitymatched cohort

\begin{tabular}{|c|c|c|c|c|}
\hline & All & Very early-VPs $(n=93)$ & Delayed-VPs $(n=93)$ & $p$ \\
\hline \multicolumn{5}{|l|}{ General characteristics } \\
\hline Age, years & $64(52-74)$ & $63(51-74)$ & $65(53-75)$ & 0.55 \\
\hline \multicolumn{5}{|l|}{ Male sex, $n(\%)$} \\
\hline Weight, kg & $69(58-77)$ & $70(57-80)$ & $65(59-72)$ & 0.08 \\
\hline APACHE $\|$ & $16(13-21)$ & $16(13-19)$ & $16(13-23)$ & 0.22 \\
\hline SOFA day 1 & $9(7-12)$ & $9(8-12)$ & $10(7-12)$ & 0.93 \\
\hline \multicolumn{5}{|l|}{ Infection source, $n(\%)$} \\
\hline Lung & $60(32.4)$ & $33(35.9)$ & $27(29.0)$ & 0.35 \\
\hline Genitourinary & $33(17.7)$ & 17 (18.3) & $16(17.2)$ & 1.00 \\
\hline Abdominal & $64(34.4)$ & $29(31.2)$ & 35 (37.6) & 0.44 \\
\hline Soft tissue & $17(9.1)$ & $9(9.7)$ & $8(8.6)$ & 1.00 \\
\hline Bacteremia & $39(21.0)$ & 17 (18.3) & $22(23.7)$ & 0.47 \\
\hline Other & $11(5.9)$ & $7(7.5)$ & $4(4.3)$ & 0.54 \\
\hline Origin & & & & 0.56 \\
\hline Emergency room & $135(72.6)$ & $66(71.0)$ & $69(74.2)$ & \\
\hline General ward & $24(12.9)$ & $11(11.8)$ & $13(14.0)$ & \\
\hline Intensive care unit & $27(14.5)$ & $16(17.2)$ & $11(11.8)$ & \\
\hline \multicolumn{5}{|l|}{ Comorbidities, n (\%) } \\
\hline Hypertension & $73(39.2)$ & 34 (36.6) & 39 (41.9) & 0.55 \\
\hline Coronary disease & $9(4.8)$ & $4(4.3)$ & $5(5.4)$ & 1.00 \\
\hline Chronic heart failure & $15(8.1)$ & $7(7.5)$ & $8(8.6)$ & 1.00 \\
\hline ESRF & $12(6.5)$ & $5(5.4)$ & $7(7.5)$ & 0.77 \\
\hline Previous stroke & $3(1.6)$ & $3(3.2)$ & $0(0.0)$ & 0.25 \\
\hline Chronic atrial fibrillation & $12(6.5)$ & $12(6.5)$ & $12(6.5)$ & 1.00 \\
\hline Diabetes & $36(19.4)$ & $18(19.4)$ & $18(19.4)$ & 1.00 \\
\hline Cancer & $38(20.4)$ & $21(22.6)$ & $17(18.3)$ & 0.59 \\
\hline COPD & $20(10.8)$ & $14(15.1)$ & $6(6.5)$ & 0.10 \\
\hline Chronic use steroids & $28(15.1)$ & $9(9.7)$ & $19(20.4)$ & 0.06 \\
\hline Cirrhosis & $12(6.5)$ & $4(4.3)$ & $8(8.6)$ & 0.16 \\
\hline Acute myocardial infarction & $3(1.6)$ & $2(2.2)$ & $1(1.1)$ & 1.00 \\
\hline Acute heart failure & $12(6.5)$ & $8(8.6)$ & $4(4.3)$ & 0.37 \\
\hline Acute stroke & $6(3.2)$ & $2(2.2)$ & $4(4.3)$ & 0.68 \\
\hline Acute atrial fibrillation & $9(4.8)$ & $2(2.2)$ & $7(7.5)$ & 0.17 \\
\hline Septic shock definition & & & & 0.19 \\
\hline Sepsis + VP + hyperlactatemia, $n(\%)$ & $127(68.3)$ & $64(68.8)$ & $63(67.7)$ & \\
\hline Sepsis + VP, $n(\%)$ & $59(31.7)$ & $29(31.2)$ & $30(32.3)$ & \\
\hline \multicolumn{5}{|l|}{ Supportive/rescue therapies } \\
\hline Steroid use, $n(\%)$ & $114(61.3)$ & 57 (61.3) & $57(61.3)$ & 1.00 \\
\hline Vasopressin use, $n(\%)$ & $63(33.9)$ & $29(31.2)$ & 34 (36.6) & 0.54 \\
\hline Acute RRT & $35(27.6)$ & $18(28.1)$ & $17(27.0)$ & 0.50 \\
\hline
\end{tabular}


Table 1 General characteristics, hemodynamics, perfusion parameters, fluids, vasopressors, and outcomes for the propensitymatched cohort (Continued)

\begin{tabular}{|c|c|c|c|c|}
\hline & All & Very early-VPs $(n=93)$ & Delayed-VPs $(n=93)$ & $p$ \\
\hline \multicolumn{5}{|l|}{ Time intervals } \\
\hline \multicolumn{5}{|l|}{ Up to VPs } \\
\hline From first hypotension to VPs & $2(0-4)$ & $1(0-2)$ & $3(2-5)$ & $<0.001$ \\
\hline From FRLoad to VPs & $0(0-3)$ & $0(0-1)$ & $3(1-4)$ & $<0.001$ \\
\hline \multicolumn{5}{|l|}{ Up to ICU admission } \\
\hline From VPs to ICU admission & $2(0-4)$ & $1(0-3)$ & $1(0-4)$ & 0.87 \\
\hline From first hypotension to ICU admission & $3(1-4)$ & $3(1-4)$ & $3(2-4)$ & 0.91 \\
\hline From FRLoad to ICU admission & $2(0-4)$ & $2(1-3)$ & $2(1-3)$ & 0.78 \\
\hline \multicolumn{5}{|l|}{ Up to antibiotic start } \\
\hline From first hypotension to antibiotics & $2(0-5)$ & $3(1-5)$ & $1(-3-5)$ & 0.04 \\
\hline \multicolumn{5}{|l|}{ Hemodynamics, perfusion parameters } \\
\hline \multicolumn{5}{|l|}{ At FRLoad } \\
\hline SAP & $88(78-98)$ & $89(79-100)$ & $88(77-97)$ & 0.61 \\
\hline DAP & $47(40-55)$ & $47(41-55)$ & $47(40-54)$ & 0.90 \\
\hline MAP & $59(54-65)$ & $59(54-67)$ & $60(55-66)$ & 0.74 \\
\hline $\mathrm{HR}$ & $105(90-118)$ & $103(90-118)$ & $106(90-118)$ & 0.73 \\
\hline PP & $40(30-53)$ & $41(31-54)$ & $40(30-50)$ & 0.73 \\
\hline DSI & $2.26(1.84-2.68)$ & $2.13(1.81-2.56)$ & $2.12(1.80-2.56)$ & 0.91 \\
\hline \multicolumn{5}{|l|}{ At VPs } \\
\hline SAP & $89(82-102)$ & $92(83-102)$ & $88(82-100)$ & 0.22 \\
\hline DAP & $48(42-55)$ & $48(41-54)$ & $48(42-55)$ & 0.85 \\
\hline MAP & $57(55-66)$ & $57(56-59)$ & $57(55-59)$ & 0.57 \\
\hline$H R$ & $102(87-118)$ & $100(87-118)$ & $104(89-117)$ & 0.73 \\
\hline PP & $41(32-53)$ & $43(31-55)$ & $41(34-50)$ & 0.56 \\
\hline DSI & $2.17(1.71-2.56)$ & $2.17(1.70-2.62)$ & $2.17(1.75-2.60)$ & 0.83 \\
\hline $\mathrm{pH}$ arterial & $7.33(7.26-7.39)$ & $7.32(7.25-7.39)$ & $7.34(7.26-7.39)$ & 0.50 \\
\hline BE arterial & $-8.0(-11.9$ to -4.1$)$ & $-7.8(-11.4$ to -3.9$)$ & $-8.2(-12.0$ to -4.2$)$ & 0.43 \\
\hline $\mathrm{SvO}_{2}, \%, n$ & $71.5(64.5-79.5), 96$ & $72.2(62.8-80.5), 46$ & 71.5 (68.0-78.5), 50 & 0.67 \\
\hline $\mathrm{Pv}-\mathrm{aCO}, \mathrm{mmHg}, n$ & $4.4(3.5-6.4), 95$ & $4.8(3.8-6.1), 46$ & $4.1(3.5-6.4), 49$ & 0.69 \\
\hline $\mathrm{PvaCO}_{2} / \mathrm{Da}-\mathrm{vO}_{2}$ ratio, $n$ & $1.41(1.01-1.98), 79$ & $1.44(1.01-1.93), 41$ & $1.38(1.02-2.14), 39$ & 0.87 \\
\hline Lactate initial, $\mathrm{mmol} / \mathrm{L}, n$ & $2.4(1.5-4.5), 186$ & $2.4(1.6-4.2), 93$ & $2.6(1.3-4.6), 93$ & 0.84 \\
\hline Lactate $6 \mathrm{H}, \mathrm{mmol} / \mathrm{L}$ & $2.0(1.1-3.8), 186$ & $1.9(1.1-3.2), 93$ & $2.1(1.1-4.0), 93$ & 0.55 \\
\hline Lactate $24 \mathrm{H}, \mathrm{mmol} / \mathrm{L}, \mathrm{n}$ & $1.7(1.1-3.2), 158$ & $1.6(1.0-2.7), 80$ & $1.9(1.1-4.5), 78$ & 0.04 \\
\hline CVP at $\mathrm{VP}, \mathrm{mmHg}, n$ & $7(5-12), 29$ & $11(7-13), 11$ & $6(4-9), 18$ & 0.09 \\
\hline $\mathrm{CVP}$ at $6 \mathrm{H}, \mathrm{mmHg}, n$ & $8(5-12), 82$ & $7(5-12), 40$ & $8(5-12), 42$ & 0.98 \\
\hline $\mathrm{CVP}$ at $24 \mathrm{H}, \mathrm{mmHg}, n$ & $8(6-13), 107$ & $8(6-12), 52$ & $10(6-15), 55$ & 0.28 \\
\hline \multicolumn{5}{|l|}{ Fluids/VP/inotropics } \\
\hline \multicolumn{5}{|l|}{ Cumulated volume of resuscitation fluids, $\mathrm{mL}$} \\
\hline FRLoad to VPs & $590(0-1565)$ & $0(0-500)$ & $1500(650-2300)$ & $<0.001$ \\
\hline VPs to $2 \mathrm{H}$ & $1000(450-1900)$ & $500(200-1100)$ & $1700(1000-2700)$ & $<0.001$ \\
\hline VPs to $4 \mathrm{H}$ & $1230(500-2350)$ & $700(300-1500)$ & $1800(1000-2880)$ & $<0.001$ \\
\hline VPs to $6 \mathrm{H}$ & $1500(750-2500)$ & $900(500-1500)$ & $2000(1400-3100)$ & $<0.001$ \\
\hline VPs to $8 \mathrm{H}$ & $1750(900-3000)$ & $1100(500-1900)$ & $2600(1600-3800)$ & $<0.001$ \\
\hline
\end{tabular}


Table 1 General characteristics, hemodynamics, perfusion parameters, fluids, vasopressors, and outcomes for the propensitymatched cohort (Continued)

\begin{tabular}{|c|c|c|c|c|}
\hline & All & Very early-VPs $(n=93)$ & Delayed-VPs $(n=93)$ & $p$ \\
\hline \multicolumn{5}{|c|}{ Cumulated volume of resuscitation fluids, $\mathrm{mL} / \mathrm{kg}$} \\
\hline FRLoad to VPs & $8.8(0.0-25.0)$ & $0.0(0.0-8.8)$ & $21.9(9.0-37.0)$ & $<0.001$ \\
\hline VPs to $2 \mathrm{H}$ & $16.0(6.3-30.0)$ & $7.3(3.2-17.8)$ & $25.0(15.1-41.8)$ & $<0.001$ \\
\hline VPs to $4 \mathrm{H}$ & $18.7(8.1-33.3)$ & $10.0(4.3-21.6)$ & $28.3(17.1-45.4)$ & $<0.001$ \\
\hline VPs to $6 \mathrm{H}$ & $23.1(10.0-38.5)$ & $12.5(6.9-24.1)$ & $28.6(21.9-50.0)$ & $<0.001$ \\
\hline VPs to $8 \mathrm{H}$ & $25.9(12.5-44.5)$ & $16.7(8.6-27.3)$ & $42.5(24.3-58.1)$ & $<0.001$ \\
\hline \multicolumn{5}{|l|}{ Delta of resuscitation fluids, $\mathrm{mL}$} \\
\hline VPs to $2 \mathrm{H}$ & $175(0-500)$ & $200(0-500)$ & $0(0-400)$ & 0.16 \\
\hline $2 \mathrm{H}$ to $4 \mathrm{H}$ & $0(0-300)$ & $0(0-400)$ & $0(0-300)$ & 0.92 \\
\hline $4 \mathrm{H}$ to $6 \mathrm{H}$ & $0(0-370)$ & $0(0-300)$ & $0(0-400)$ & 0.11 \\
\hline $6 \mathrm{H}$ to $8 \mathrm{H}$ & $0(0-500)$ & $0(0-300)$ & $300(0-630)$ & $<0.001$ \\
\hline \multicolumn{5}{|l|}{ Net fluid balance } \\
\hline At FRLoad & $552(0-2507)$ & $310(0-1750)$ & $340(0-2500)$ & 0.19 \\
\hline At VPs & $1989(661-3700)$ & $760(10-2300)$ & $2090(920-3260)$ & $<0.001$ \\
\hline At $6 \mathrm{H}$ & 2594 (1469-5055) & $1760(1070-3410)$ & $2680(1470-4480)$ & $<0.001$ \\
\hline At $24 \mathrm{H}$ & 4762 (3197-7049) & $3905(2370-5100)$ & $5400(3790-7290)$ & $<0.001$ \\
\hline Norepinephrine max. dose, $\mu \mathrm{g} / \mathrm{kg} / \mathrm{min}$ & $0.26(0.13-0.48)$ & $0.26(0.11-0.45)$ & $0.28(0.15-0.53)$ & 0.32 \\
\hline Dobutamine max. dose, $\mu \mathrm{g} / \mathrm{kg} / \mathrm{min}, n$ & $5.2(3.0-10.2), 28$ & $5.0(3.7-7.0), 13$ & $6.6(3.0-11.6), 15$ & 0.55 \\
\hline \multicolumn{5}{|l|}{ Clinical outcomes } \\
\hline LOS-ICU & $9(5-17)$ & $9(5-18)$ & $8(4-17)$ & 0.30 \\
\hline LOS-Hospital & $16(7-32)$ & $17(9-32)$ & $15(6-30)$ & 0.11 \\
\hline Mechanical ventilation-free days & $22(0-28)$ & $23(14-28)$ & $21(0-26)$ & 0.03 \\
\hline RRT-free days & $6(0-18)$ & $8(1-18)$ & $1(0-13)$ & 0.26 \\
\hline Mortality of 28 days, $n(\%)$ & $53(28.5)$ & $17(18.3)$ & $36(38.7)$ & 0.03 \\
\hline
\end{tabular}

APACHE I/ acute physiology and chronic health evaluation, SOFA sequential organ failure assessment, CHF cardiac heart failure, ESRF end-stage renal failure, COPD chronic obstructive pulmonary disease, VP vasopressor, VPs vasopressor start, FRLoad first fluid load with resuscitative intention, SAP systolic arterial pressure, DAP diastolic arterial pressure, MAP mean arterial pressure, $H R$ heart rate, $P P$ pulse pressure, $D S I$ diastolic shock index (HR to DAP ratio), $B E$ base excess, SVO ${ }_{2}$ oxygen venous saturation, $\mathrm{Pv}-a \mathrm{CO}_{2}$ venous-to-arterial carbon dioxide difference, $\mathrm{PvaCO} / \mathrm{Da}-\mathrm{vO}_{2}$ ratio venous-arterial carbon dioxide to arterial-venous oxygen differences ratio, CVP central venous pressure, LOS-ICU intensive care unit - length of stay, LOS-Hospital hospital - length of stay, RRT renal replacement therapy

*Including only patients receiving renal replacement therapy at least for one session

All patients included in our study followed a quantitative resuscitation protocol in which fluid responsiveness was repeatedly tested during the initial resuscitation period aiming to achieve some tissue perfusion goals. Remarkably, although receiving lower amount of resuscitation fluids for achieving the same resuscitation goals, patients in the VE-VPs group had a significantly lower mortality, which is in line with studies showing that norepinephrine may reduce preload dependency [45] due to recruitment of preload reserve from the unstressed blood volume, thus leading to lower fluid requirement. Unfortunately, although biologically plausible, the observational nature of our study does not allow confirming whether a more precocious mobilization from nonstressed to stressed blood volume by early introduction of vasopressors might have influenced the requirement of resuscitation fluids.
A previous observational study suggested that delayed introduction of VP support after initial fluid loading [46] might be related with worse clinical outcomes. In addition to a longer time of pre-vasopressor hypotension, the delayed vasopressor group was subjected to a more severe hypotension even after the introduction of the vasopressor support itself, which hinders the actual effect of the timing of vasopressor use [46]. In contrast, in our study, hypotension was rapidly corrected in both VE-VPs and DVPs groups, and the time-course of mean arterial pressure was quite similar between them, at least after vasopressor introduction. Nevertheless, time elapsed between the first hypotension episode and the introduction of VP support was significantly shortened in the VE-VPs, which is in line with studies suggesting that shorter hypotension times are associated with better outcomes in septic shock [33, 34]. Unfortunately, we recorded blood pressure at discrete 


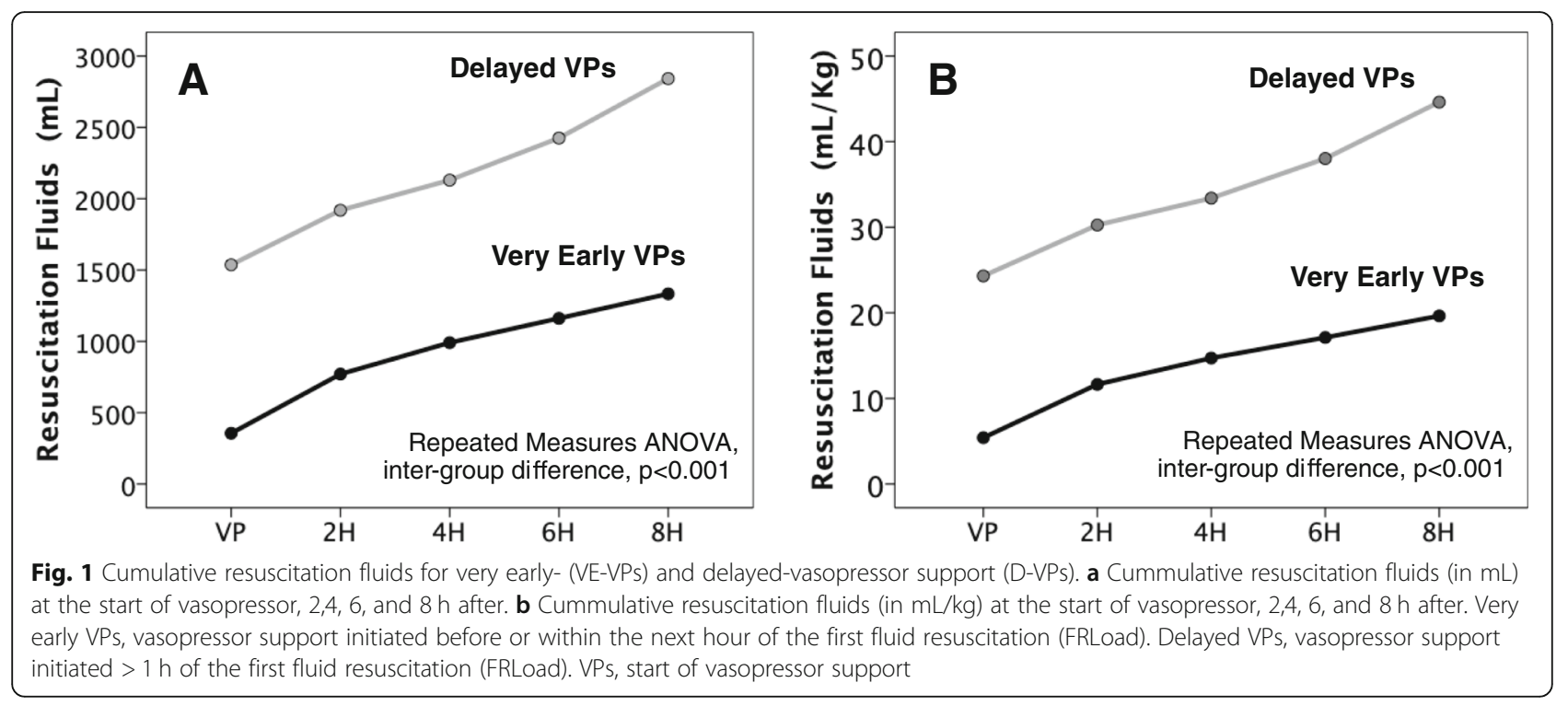

intervals, which prevents establishing precisely the number of minutes spent in hypotension in each group.

A recent randomized trial addressed the issue about the early introduction of norepinephrine in patients with septic shock [36]. Nevertheless, very low and non-titrated doses of norepinephrine were used while the idea of administering a fixed dose of fluids before to start of the "non-blinded" vasopressor support was maintained. Importantly, the rate of achievement of lactate clearance after $6 \mathrm{~h}$ of resuscitation was extremely low and did not differ from those not receiving the study low dose of vasopressor. In contrast with this, our patients received a MAP-targeted dose of norepinephrine along with other resuscitation maneuvers directed to restore tissue perfusion. Furthermore, early introduction of VPs in our study

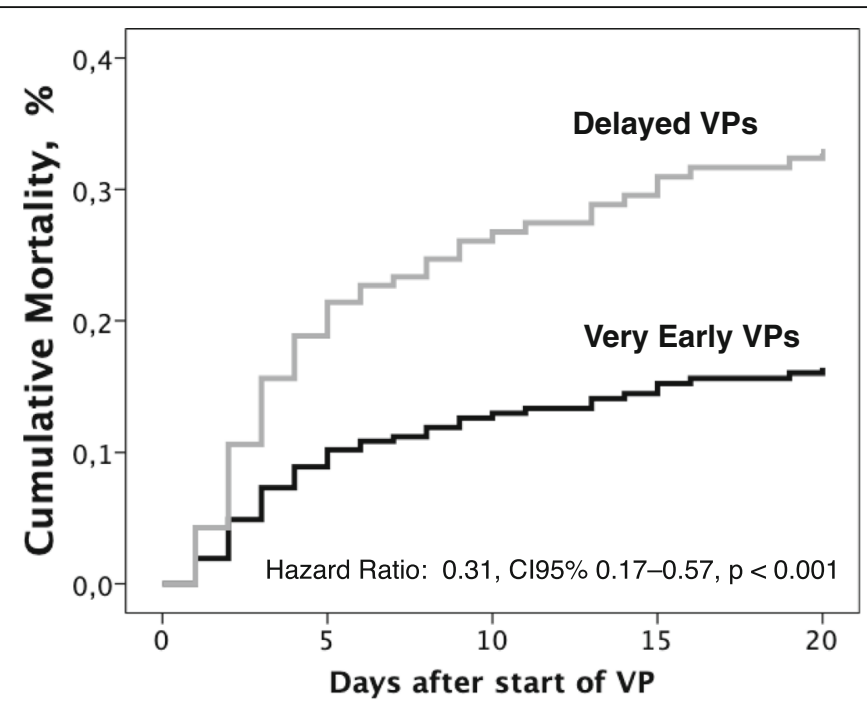

\begin{tabular}{|l|l|l|l|l|l|}
\hline VE-VPs & 93 & 80 & 78 & 78 & 76 \\
\hline D-VPs & 93 & 70 & 63 & 57 & 56 \\
\hline
\end{tabular}

Fig. 2 Cox proportional hazard model for risk of death at day 28 for very early- (VE-VPs) and delayed-vasopressor support (D-VPS). The Cox proportional hazards model was adjusted by SOFA score at day 1, the presence of hyperlactatemia (septic shock according to Sepsis 3.0 definition), delay time of antibiotic administration, and the net fluid balance at $24 \mathrm{~h}$. Very early VPs, vasopressor support initiated before or within the next hour of the first fluid resuscitation (FRLoad). Delayed VPs, vasopressor support initiated $>1 \mathrm{~h}$ of the first fluid resuscitation (FRLoad). VPs, start of vasopressor support 
Table 2 Multivariate Cox regression for 28-day mortality (propensity-matched population: $n=186$ )

\begin{tabular}{llll}
\hline & HR & $95 \% \mathrm{Cl}$ & $p$ \\
\hline Net fluid balance & 1.00 & $1.00-1.00$ & $<0.001$ \\
Steroids use $^{*}$ & 4.66 & $1.94-11.18$ & 0.001 \\
Hyperlactatemia** $^{*}$ & 3.61 & $1.41-9.22$ & 0.007 \\
VE-VPs & 0.31 & $0.17-0.57$ & $<0.001$
\end{tabular}

SOFA Sequential Organ Failure Assessment, VE-VPs very early start of vasopressor support

*Low-dose steroids (200-300 mg/day) used in the context of shock

** Lactate levels $>2.0 \mathrm{mmol} / \mathrm{L}$ (Third International Consensus Definitions for Sepsis and Septic Shock-Sepsis 3.0-considers the presence of suspected infection accompanying life-threatening organ dysfunction, use of

vasopressors, MAP $<65 \mathrm{mmHg}$, and lactate levels $>2 \mathrm{mmol} / \mathrm{L}$ as septic shock)

was not directed by the idea of completing a predetermined volume of fluids in advance.

Early use of vasopressors could change the course of hemodynamics in septic shock. A recent experimental model of endotoxemia suggested that fluid resuscitation might paradoxically increase vasopressor requirements compared with an early and isolated use of VP [11]. In the same line, our data suggests that lower doses of norepinephrine could be required when VP support is introduced very early, at least during the first $6 \mathrm{~h}$ of resuscitation (see Additional file 1: Figure S4). Therefore, the early onset of VP would seem to prevent the progression of circulatory dysfunction.

There are concerns about the effect of VP on splanchnic perfusion when hypovolemia coexists $[47,48]$. Meanwhile, some experimental studies have suggested potential benefits of early combination of vasopressors and fluids on splanchnic blood flow [25]. Due to the nature of our study, it is not possible to discard the concurrence of hypovolemia. Nevertheless, fluid resuscitation in both VE-VPs and D-VPs groups was guided by using fluid responsiveness test and clinical parameters, targeting the restoration of systemic and peripheral perfusion variables. In our study, the intervention consisting of very early use of vasopressors was not associated with an excess of acute kidney injury or increased requirements of acute renal replacement therapies. In addition, most patients initially received vasopressor support through peripheral veins for a few minutes up to a central venous line was obtained, which was not associated with major complications. Finally, although severe digital ischemia cases were not observed, other side effects such as myocardial ischemia were not systematically searched.

Our study should not be misinterpreted. It did not evaluate whether a restrictive fluid administration, tolerating worse hemodynamic variables may be beneficial. On the contrary, it evaluated the effects of the rapid introduction of vasopressors, correcting promptly hypotension, therefore limiting the amount of fluids administered while otherwise achieving similar hemodynamic goals. Indeed, fluids were administered based on the same criteria of fluid responsiveness in all patients. In addition, this study is not a probe for the "1-h bundle" recently proposed [8] but rather a hypothesis generator about the benefits of early start of vasopressors in septic shock, emphasizing that patients of the VE-VPs group received the immediate start of norepinephrine without completing a predefined volume or resuscitation fluids.

Nevertheless, important limitations should be mentioned. First, the nature of this study and, therefore, the lack of control by randomization and blinding might limit the validity of conclusions. Admittedly, although propensity scores were constructed incorporating baseline characteristics likely influencing the decision for an early start of VP support, other nonidentifiable potential factors might not have been included. In addition, the small sample size introduces a risk of missing important differences at baseline that might contribute to the observed differences in mortality instead of early vasopressor introduction. Second, also due to the nature of our study, it is not possible to establish causal mechanisms leading to differences in clinical outcomes between the groups. Nevertheless, we speculate that the combination of shortening of hypotension time, lower pre-vasopressor and post-vasopressor fluid requirements, and, consequently, lower net fluid accumulation could have influenced clinical outcomes. Third, acute renal failure, acute renal replacement therapies, and digital ischemia were easily tracked. However, other adverse consequences of the early use of vasopressors cannot be ruled out. Fourth, we are not able to identify if the decision of the early start of vasopressors relied on some particular doctors, which could constitute a potential factor of confusion. Finally, although the single-center design might restrict a potential generalization of our results, exclusions were very limited so that this trial reflects the overall spectrum of patients with septic shock. Furthermore, the biological plausibility of these results, the potential physiological mechanisms of early introduction of VPs, and the agreement with recent experimental observations deserve future research efforts.

\section{Conclusions}

A very early start of vasopressor support was associated with a lower amount of resuscitation fluids, less fluid accumulation, and shortening of hypotension times. Very early start of vasopressors even before completing a predefined volume of fluid resuscitation seems to be a safe intervention with potential beneficial effects on clinical outcomes. 


\section{Supplementary information}

Supplementary information accompanies this paper at https://doi.org/10. 1186/s13054-020-2756-3

Additional file 1: Figure S1. Selection of patients. Table S1. ESTROBE Statement-Checklist for observational studies. Table S2. General characteristics, hemodynamics, perfusion parameters, fluids, vasopressors and clinical outcomes for the complete (pre-matched) population. Figure S2. Time-course of mean arterial pressures (matched cohort). Figure S3. Net fluid balance from the first resuscitation load up to 24 hours (matched cohort). Figure S4. Time-course of norepinephrine for Very Earlyand Delayed-VPs from 2 to 8 hours (matched cohort). Figure S5. Timecourse of diastolic shock index (HR:DAP ratio) for Very Early- and DelayedVPs from start of vasopressors up to 8 hours (matched cohort). Figure S6. Time-course of Pulse Pressure for Very Early- and Delayed-VPs from start of vasopressors up to 8 hours (matched cohort). Figure S7 a. Cox-proportional hazard model for risk of death at day-28 for Very Early- and Delayed-VPs in patients fulfilling the septic shock criteria according to the Sepsis 3.0 definition (matched cohort). Figure S7 b. Cox-proportional hazard model for risk of death at day-28 for Very Early- and Delayed-VPs in patients NO fulfilling the septic shock criteria according to the Sepsis 3.0 definition (sepsis-related acute cardiovascular dysfunction). Table S3. Multivariate Cox regression for 28-day mortality (non-matched population: $n=337$ ). Table S4. Multivariate Cox regression for 28-day mortality (propensity-matched population including patients using VPs for $<6 \mathrm{H}: n=216)$.

\section{Abbreviations}

D-VPs: Delayed start of vasopressor support; FHypo: First hypotension episode; FRLoad: First fluid load with resuscitative intention; MAP: Mean arterial pressure; SOFA: Sequential Organ Failure Assessment Score; VEVPs: Very-early start of vasopressor support; VP: Vasopressor; VPs: Start of vasopressor support

\section{Acknowledgements}

The authors thank Dr. Fernando Rosso (CIC, Fundación Valle del LiliUniversidad Icesi, Cali, Colombia) and Dra. Yuri Takeuchi (Universidad Icesi Fundación Valle del Lili) for their unconditional support to this project.

\section{Authors' contributions}

GAOT, GH, and JB contributed to the literature search of the study. GAOT, IA, $L E C T, R M N, E Q, H J M N$, JERY, and JLA contributed to the data acquisition of the study. GAOT, GH, AISO, LECT, RMN, EQ, HJ-MN, JER, JLA, JLT, and JB contributed to the data analysis and interpretation of the study. GAOT, GH, JLT, $D D B$, and JB contributed to the critical review of the study. GAOT, JLT, GH, $D D B$, and JB contributed to the conception, hypothesis delineation, and design of the study. All authors read and approved the final manuscript.

\section{Funding}

The current study received logistic support from the Centro de Investigaciones Clínicas - Fundación Valle del Lili, Cali, Colombia.

\section{Availability of data and materials}

The datasets generated and/or analyzed during the current study are not publicly available as recommended by the local ethical and research committee involving human beings (Fundación Valle del Lili, Cali, Colombia) but could be available from the corresponding author on reasonable request and under prior approval by such committee.

\section{Ethics approval and consent to participate}

The ethical and research committee involving human beings approved the current study (Protocol number 1238, IRB/EC approval number 099-2018, Fundación Valle del Lili, Cali, Colombia).

\section{Consent for publication}

Not applicable

\section{Competing interests}

The authors declare that they have no competing interests.

\section{Author details}

'Department of Intensive Care Medicine, Fundación Valle del Lili, Universidad Icesi, Cali, Colombia. ${ }^{2}$ Translational Medicine Laboratory in Critical Care and Advanced Trauma Surgery, Fundación Valle del Lili, Universidad Icesi, Cali, Colombia. ${ }^{3}$ Departamento de Medicina Intensiva, Pontificia Universidad Católica de Chile, Santiago, Chile. ${ }^{4}$ Service de Réanimation Médicale, Hôpital Bicêtre, Hôpitaux Universitaires Paris-Sud, Assistance Publique Hôpitaux de Paris, Université Paris-Sud, Paris, France. ${ }^{5}$ HCor Research Institute, São Paulo, Brazil. ' Intensive Care Department, CHIREC Hospitals, Université Libre de Bruxelles, Brussels, Belgium. ${ }^{7}$ Department of Intensive Care Adults, Erasmus MC University Medical Center, Rotterdam, The Netherlands. ${ }^{8}$ Department of Pulmonary and Critical Care, New York University, New York, USA. ${ }^{\circ}$ Division of Pulmonary, Allergy, and Critical Care Medicine, Columbia University Medical Center, New York, USA.

Received: 5 August 2019 Accepted: 29 January 2020

Published online: 14 February 2020

\section{References}

1. Rhodes A, Evans LE, Alhazzani W, Levy MM, Antonelli M, Ferrer R, Kumar A, Sevransky JE, Sprung CL, Nunnally ME, et al. Surviving Sepsis Campaign: International Guidelines for Management of Sepsis and Septic Shock: 2016. Crit Care Med. 2017:45(3):486-552.

2. Cecconi M, De Backer D, Antonelli M, Beale R, Bakker J, Hofer C, Jaeschke R, Mebazaa A, Pinsky MR, Teboul JL, et al. Consensus on circulatory shock and hemodynamic monitoring. Task force of the European Society of Intensive Care Medicine. Intensive Care Med. 2014;40(12):1795-815.

3. Levy MM, Dellinger RP, Townsend SR, Linde-Zwirble WT, Marshall JC, Bion J, Schorr C, Artigas A, Ramsay G, Beale R, et al. The Surviving Sepsis Campaign: results of an international guideline-based performance improvement program targeting severe sepsis. Crit Care Med. 2010;38(2):367-74.

4. Levy MM, Rhodes A, Phillips GS, Townsend SR, Schorr CA, Beale R, Osborn T, Lemeshow S, Chiche JD, Artigas A, et al. Surviving Sepsis Campaign: association between performance metrics and outcomes in a 7.5-year study. Crit Care Med. 2015:43(1):3-12

5. Peake SL, Delaney A, Bailey M, Bellomo R, Cameron PA, Cooper DJ, Higgins AM, Holdgate A, Howe BD, Webb SA, et al. Goal-directed resuscitation for patients with early septic shock. N Engl J Med. 2014;371(16):1496-506.

6. Mouncey PR, Osborn TM, Power GS, Harrison DA, Sadique MZ, Grieve RD, Jahan R, Harvey SE, Bell D, Bion JF, et al. Trial of early, goal-directed resuscitation for septic shock. N Engl J Med. 2015:372(14):1301-11.

7. Yealy DM, Kellum JA, Huang DT, Barnato AE, Weissfeld LA, Pike F, Terndrup T, Wang HE, Hou PC, LoVecchio F, et al. A randomized trial of protocolbased care for early septic shock. N Engl J Med. 2014;370(18):1683-93.

8. Chen AX, Simpson SQ, Pallin DJ. Sepsis Guidelines. N Engl J Med. 2019; 380(14):1369-71.

9. Seymour CW, Gesten F, Prescott HC, Friedrich ME, Iwashyna TJ, Phillips GS, Lemeshow S, Osborn T, Terry KM, Levy MM. Time to treatment and mortality during mandated emergency care for sepsis. N Engl J Med. 2017:376(23):2235-44

10. Maitland K, George EC, Evans JA, Kiguli S, Olupot-Olupot P, Akech SO, Opoka RO, Engoru C, Nyeko R, Mtove G, et al. Exploring mechanisms of excess mortality with early fluid resuscitation: insights from the FEAST trial. BMC Med. 2013;11(1):68.

11. Byrne L, Obonyo NG, Diab SD, Dunster KR, Passmore MR, Boon AC, See Hoe L, Pedersen S, Hashairi Fauzi M, Pretti Pimenta L, et al. Unintended consequences; fluid resuscitation worsens shock in an ovine model of endotoxemia. Am J Respir Crit Care Med. 2018.

12. Boyd JH, Forbes J, Nakada TA, Walley KR, Russell JA. Fluid resuscitation in septic shock: a positive fluid balance and elevated central venous pressure are associated with increased mortality. Crit Care Med. 2011;39(2):259-65.

13. Micek ST, McEvoy C, McKenzie M, Hampton N, Doherty JA, Kollef MH. Fluid balance and cardiac function in septic shock as predictors of hospital mortality. Crit Care. 2013;17(5):R246.

14. Sadaka F, Juarez M, Naydenov S, O'Brien J. Fluid resuscitation in septic shock: the effect of increasing fluid balance on mortality. J Intensive Care Med. 2014;29(4):213-7.

15. Acheampong A, Vincent $J$ L. A positive fluid balance is an independent prognostic factor in patients with sepsis. Crit Care. 2015:19:251.

16. de Oliveira FS, Freitas FG, Ferreira EM, de Castro I, Bafi AT, de Azevedo LC, Machado FR. Positive fluid balance as a prognostic factor for mortality and acute kidney injury in severe sepsis and septic shock. J Crit Care. 2015;30(1):97-101. 
17. Kelm DJ, Perrin JT, Cartin-Ceba R, Gajic O, Schenck L, Kennedy CC. Fluid overload in patients with severe sepsis and septic shock treated with early goal-directed therapy is associated with increased acute need for fluid-related medical interventions and hospital death. Shock. 2015;43(1):68-73.

18. Sakr Y, Rubatto Birri PN, Kotfis K, Nanchal R, Shah B, Kluge S, Schroeder ME, Marshall JC, Vincent JL, Investigators ICON. Higher fluid balance increases the risk of death from sepsis: results from a large international audit. Crit Care Med. 2017:45(3):386-94.

19. Vincent JL, Sakr Y, Sprung CL, Ranieri VM, Reinhart K, Gerlach H, Moreno R, Carlet J, Le Gall JR, Payen D, et al. Sepsis in European intensive care units: results of the SOAP study. Crit Care Med. 2006;34(2):344-53.

20. Murphy CV, Schramm GE, Doherty JA, Reichley RM, Gajic O, Afessa B, Micek $\mathrm{ST}$, Kollef $\mathrm{MH}$. The importance of fluid management in acute lung injury secondary to septic shock. Chest. 2009;136(1):102-9.

21. Sirvent JM, Ferri C, Baró A, Murcia C, Lorencio C. Fluid balance in sepsis and septic shock as a determining factor of mortality. Am J Emerg Med. 2015;33(2):186-9.

22. Silversides JA, Major E, Ferguson AJ, Mann EE, McAuley DF, Marshall JC, Blackwood B, Fan E. Conservative fluid management or deresuscitation for patients with sepsis or acute respiratory distress syndrome following the resuscitation phase of critical illness: a systematic review and meta-analysis. Intensive Care Med. 2017:43(2):155-70

23. Smith SH, Perner A. Higher vs. lower fluid volume for septic shock: clinical characteristics and outcome in unselected patients in a prospective, multicenter cohort. Crit Care. 2012;16(3):R76.

24. Marik PE, Linde-Zwirble WT, Bittner EA, Sahatjian J, Hansell D. Fluid administration in severe sepsis and septic shock, patterns and outcomes: an analysis of a large national database. Intensive Care Med. 2017;43(5):625-32.

25. Sennoun N, Montemont C, Gibot S, Lacolley P, Levy B. Comparative effects of early versus delayed use of norepinephrine in resuscitated endotoxic shock. Crit Care Med. 2007;35(7):1736-40.

26. Hamzaoui O, Georger JF, Monnet X, Ksouri H, Maizel J, Richard C, Teboul JL. Early administration of norepinephrine increases cardiac preload and cardiac output in septic patients with life-threatening hypotension. Crit Care. 2010;14(4):R142.

27. Hamzaoui O, Jozwiak M, Geffriaud T, Sztrymf B, Prat D, Jacobs F, Monnet X, Trouiller P, Richard C, Teboul JL. Norepinephrine exerts an inotropic effect during the early phase of human septic shock. Br J Anaesth. 2018;120(3):517-24.

28. De Backer D, Pinsky M. Norepinephrine improves cardiac function during septic shock, but why? Br J Anaesth. 2018;120(3):421-4

29. Thooft A, Favory R, Salgado DR, Taccone FS, Donadello K, De Backer D, Creteur J, Vincent JL. Effects of changes in arterial pressure on organ perfusion during septic shock. Crit Care. 2011;15(5):R222.

30. Jhanji S, Stirling S, Patel N, Hinds CJ, Pearse RM. The effect of increasing doses of norepinephrine on tissue oxygenation and microvascular flow in patients with septic shock. Crit Care Med. 2009;37(6):1961-6.

31. Georger JF, Hamzaoui O, Chaari A, Maizel J, Richard C, Teboul JL. Restoring arterial pressure with norepinephrine improves muscle tissue oxygenation assessed by near-infrared spectroscopy in severely hypotensive septic patients. Intensive Care Med. 2010;36(11):1882-9.

32. Dubin A, Pozo MO, Casabella CA, Pálizas F, Murias G, Moseinco MC, Kanoore Edul VS, Estenssoro E, Ince C. Increasing arterial blood pressure with norepinephrine does not improve microcirculatory blood flow: a prospective study. Crit Care. 2009;13(3):R92.

33. Varpula M, Tallgren M, Saukkonen K, Voipio-Pulkki LM, Pettilä V. Hemodynamic variables related to outcome in septic shock. Intensive Care Med. 2005;31(8):1066-71

34. Dünser MW, Takala J, Ulmer H, Mayr VD, Luckner G, Jochberger S, Daudel F, Lepper P, Hasibeder WR, Jakob SM. Arterial blood pressure during early sepsis and outcome. Intensive Care Med. 2009;35(7):1225-33.

35. Maheshwari K, Nathanson BH, Munson SH, Khangulov V, Stevens M, Badani $H$, Khanna AK, Sessler DI. The relationship between ICU hypotension and in-hospital mortality and morbidity in septic patients. Intensive Care Med. 2018;44(6):857-67.

36. Permpikul C, Tongyoo S, Viarasilpa T, Trainarongsakul T, Chakorn T, Udompanturak S. Early use of norepinephrine in septic shock resuscitation (CENSER). A randomized trial. Am J Respir Crit Care Med. 2019;199(9):1097-105.

37. Dellinger RP, Levy MM, Rhodes A, Annane D, Gerlach H, Opal SM, Sevransky JE, Sprung CL, Douglas IS, Jaeschke R, et al. Surviving Sepsis Campaign: international guidelines for management of severe sepsis and septic shock, 2012. Intensive Care Med. 2013;39(2):165-228.

38. Levy MM, Fink MP, Marshall JC, Abraham E, Angus D, Cook D, Cohen J, Opal SM, Vincent JL, Ramsay G, et al. 2001 SCCM/ESICM/ACCP/ATS/SIS International Sepsis Definitions Conference. Crit Care Med. 2003;31(4):1250-6.

39. Horan TC, Andrus M, Dudeck MA. CDC/NHSN surveillance definition of health care-associated infection and criteria for specific types of infections in the acute care setting. Am J Infect Control. 2008;36(5):309-32.

40. Singer M, Deutschman CS, Seymour CW, Shankar-Hari M, Annane D, Bauer M, Bellomo R, Bernard GR, Chiche JD, Coopersmith CM, et al. The Third International Consensus Definitions for Sepsis and Septic Shock (Sepsis-3). JAMA. 2016;315(8):801-10.

41. Vincent JL, de Mendonça A, Cantraine F, Moreno R, Takala J, Suter PM, Sprung CL, Colardyn F, Blecher S. Use of the SOFA score to assess the incidence of organ dysfunction/failure in intensive care units: results of a multicenter, prospective study. Working group on "sepsis-related problems" of the European Society of Intensive Care Medicine. Crit Care Med. 1998;26(11):1793-800.

42. Ait-Oufella H, Bige N, Boelle PY, Pichereau C, Alves M, Bertinchamp R, Baudel JL, Galbois A, Maury E, Guidet B. Capillary refill time exploration during septic shock. Intensive Care Med. 2014;40(7):958-64.

43. Ait-Oufella H, Bourcier S, Alves M, Galbois A, Baudel JL, Margetis D, Bige N, Offenstadt G, Maury E, Guidet B. Alteration of skin perfusion in mottling area during septic shock. Ann Intensive Care. 2013;3(1):31.

44. Sakr Y, Vincent JL, Reinhart K, Groeneveld J, Michalopoulos A, Sprung CL, Artigas A, Ranieri VM, Investigators SOiAIP. High tidal volume and positive fluid balance are associated with worse outcome in acute lung injury. Chest. 2005;128(5):3098-108.

45. Monnet X, Jabot J, Maizel J, Richard C, Teboul JL. Norepinephrine increases cardiac preload and reduces preload dependency assessed by passive leg raising in septic shock patients. Crit Care Med. 2011;39(4):689-94.

46. Bai X, Yu W, Ji W, Lin Z, Tan S, Duan K, Dong Y, Xu L, Li N. Early versus delayed administration of norepinephrine in patients with septic shock. Crit Care. 2014;18(5):532.

47. Hinder F, Stubbe HD, Van Aken H, Baba HA, Jahn UR, Brodner G, August C, Erren $M$, Booke M. Early multiple organ failure after recurrent endotoxemia in the presence of vasoconstrictor-masked hypovolemia. Crit Care Med. 2003;31(3):903-9.

48. Aneman A, Bengtsson J, Snygg J, Holm M, Pettersson A, Fändriks L. Differentiation of the peptidergic vasoregulatory response to standardized splanchnic hypoperfusion by acute hypovolaemia or sepsis in anaesthetized pigs. Acta Physiol Scand. 1999;166(4):293-300.

\section{Publisher's Note}

Springer Nature remains neutral with regard to jurisdictional claims in published maps and institutional affiliations.

\section{Ready to submit your research? Choose BMC and benefit from:}

- fast, convenient online submission

- thorough peer review by experienced researchers in your field

- rapid publication on acceptance

- support for research data, including large and complex data types

- gold Open Access which fosters wider collaboration and increased citations

- maximum visibility for your research: over $100 \mathrm{M}$ website views per year

At BMC, research is always in progress.

Learn more biomedcentral.com/submissions 